University of South Carolina

Scholar Commons

4-1997

\title{
Productive Physical Education Pedagogy Scholars: Why They Do
} It and How

\author{
Murrary F. Mitchell \\ University of South Carolina - Columbia, mmitchel@mailbox.sc.edu
}

Follow this and additional works at: https://scholarcommons.sc.edu/pedu_facpub

Part of the Education Commons

\section{Publication Info}

Published in Journal of Teaching in Physical Education, Volume 16, Issue 3, 1997, pages 278-299. http://journals.humankinetics.com/jtpe-contents (C) 1997 by Human Kinetics Publishers, Inc.

This Article is brought to you by the Physical Education, Department of at Scholar Commons. It has been accepted for inclusion in Faculty Publications by an authorized administrator of Scholar Commons. For more information, please contact digres@mailbox.sc.edu. 


\title{
Productive Physical Education Pedagogy Scholars: Why They Do It and How
}

\author{
Murray F. Mitchell \\ The University of South Carolina
}

\begin{abstract}
The purpose of this study was to determine why and how a sample of physical education teacher education (PETE) scholars manage to be productive publishers. Authors or coauthors of four or more articles in the Journal of Teaching in Physical Education (JTPE) through the 1980s $(N=24)$ responded to a mail questionnaire on why they write, why they choose to write for JTPE, what they believe to be true about themselves or their approach to writing, and any situational factors that have led to their publication success. Authors described personal motives such as publishing to meet a curiosity drive, for the enjoyment of the process, to facilitate learning, and to lead toward promotion and raises. Facilitators of the process included having access to colleagues and mentors and having a personal commitment to pursue publication. These findings are discussed with regard to insights available for administrators and novice faculty members.
\end{abstract}

Scholarly productivity is a professional behavior that is rewarded and even sought in higher education. This situation has been true in the United States since the late 1800s, tied to what Jencks and Riesman (1969) identified as the gradual rise of the university. During this evolutionary phase in higher education, Jencks and Riesman described how instructors became "less and less preoccupied with educating young people [and] more and more preoccupied with educating one another by doing scholarly research" (p. 13).

More recently, Seldin (1984) and Bowen and Schuster (1986) have suggested that research productivity and scholarly writing are not exclusively the tasks of those in research universities; rather, these tasks are also expected from faculty in state colleges and liberal arts schools. Bok (1986) has even called these tasks "the common currency of academic achievement, a currency that can be weighed and evaluated across institutional and even national boundaries" (p. 77). For purposes of this paper, the term scholarly productivity will be used to refer to work represented in professional publications. Other, broader interpretations of the concept of scholarship are beyond the scope of this paper (cf. Boyer, 1990).

Clearly, institutional rewards are in place that encourage faculty members in higher education to be productive writers. The efforts of productive scholars are

Murray F. Mitchell is with the Department of Physical Education at The University of South Carolina, Blatt Physical Education Center, Columbia, SC 29208. 
rewarded in a variety of different ways: favorable promotion and tenure decisions, higher salaries, and the esteem of colleagues (Crase, 1993). Some of these productivity incentives stem from the accompanying prestige for the associated departments and institutions, occasionally including an enhanced national and even international reputation and visibility (Clifford \& Guthrie, 1988; Creswell, 1985). Another source for scholarly production is the intrinsic drive of a personal sense of purpose or a passion for scholarly productivity (Crase, 1993).

There is, however, a paradox surrounding scholarly productivity in higher education in the United States. Even though this responsibility has been tied to the role of professor for the best part of this century, few professors appear to be involved in research and publication efforts consistently across their careers (Burch, 1989; Carnegie Foundation for the Advancement of Teaching, 1985; Ducharme \& Agne, 1982; Freeman, 1977; Ladd \& Lipset, 1976; Metzler \& Freedman, 1985; Mitchell, 1992a, 1992b; Mitchell \& Lawson, 1986; Scott, 1986).

Important questions warrant attention in light of the relationships outlined above. For example, if making publishing a role responsibility is not sufficient to motivate more faculty to produce scholarship, what moves productive scholars to write? And there is at least one more question of a more pragmatic nature warranting attention: How does one become productive? Regardless of why some faculty members are motivated to be highly productive, this behavior has consistently been rewarded with individual and departmental recognition, merit increments, promotions, and tenure. Hence, novice faculty members need guidance in how to succeed with this important role responsibility. Institutional administrators need help to identify the potential for productivity in new recruits and help to cultivate productivity in other faculty members. There are also those seeking solutions to personal and societal problems who believe that answers may lie in the work of active researchers.

The purpose of this project was to examine why and how physical education pedagogy authors remain productive by examining a major physical education teacher education (PETE) journal. The Journal of Teaching in Physical Education (JTPE) was selected for this study because of its mandate and impact. The journal was founded in the spring of 1981 by Metzler and Freedman to create "an outlet for research and topical discussion articles for the discipline of physical education teacher education" (Metzler \& Freedman, 1981, p. 1). As an indication of the impact of JTPE, the journal has been identified as one of the journals most often read by PETE faculty (Metzler \& Freedman, 1985; Mitchell, 1992b).

In the following section, two aspects of literature related to this study will be presented. First, the literature addressing why scholars choose the task of writing will be offered as background information to the study of PETE scholars. Second, the literature that exists regarding how this select group of scholars is productive will be presented.

\section{Related Literature}

\section{Why Researchers Publish}

For many researchers, publication is a logical outcome of their work. The dissemination of results appears to be an oversimplification and an incomplete explanation for why researchers publish, however. In theoretical terms, Creswell (1985) provided the following motives for authors in general: 
1. To provide visibility to the institution

2. To facilitate objectivity to the promotion and tenure process

3. To contribute to the general public knowledge base

Lawson (1990) expanded on this, hypothesizing the following motives specifically for physical education pedagogy authors:

1. To guide and improve teaching practices in school- and agency-based physical education programs

2. For employment security

3. For economic gain

4. As a result of peer pressure

5. To bring status to the department within the institution

6. To acquire personal power within the profession

7. For enjoyment

8. For curiosity and the potential for learning

9. To establish a career identity

Creswell's third and Lawson's first hypothesized motives come closest to traditional views of the value of research. Boyer (1990) framed the value of researchers and scholarship as follows:

The probing mind of the researcher is an incalculably vital asset to the academy and the world. Scholarly investigation, in all the disciplines, is at the very heart of academic life, and the pursuit of knowledge must be assiduously cultivated and defended. The intellectual excitement fueled by this quest enlivens faculty and invigorates higher learning institutions, and in our complicated, vulnerable world, the discovery of new knowledge is absolutely crucial. (p. 18)

Creswell's and Lawson's hypothesized motives indicate that there are many factors involved in the process of seeking publication. Some authors have been critical of the accumulated knowledge base, however, and many of these criticisms can be tied back to motives of researchers. In one analysis of the sport pedagogy research, for example, Lawson (1990) suggested that what currently exists can be described as "more information than knowledge" (p. 5). Lawson made the distinction between information as "messages or content available in one's environment" (p. 3) and knowledge as the result of information that is "of sufficient quality [to be] integrated into frameworks offering individual and collective (or personal and professional) meaning" (p. 3). He went on to suggest that information qualifies as knowledge only when it passes the three tests of being true, relevant, and useful for practice (p. 3). Accepting these definitions, and Lawson's (1990) characterization of the sport pedagogy research, the question of why there is more information than knowledge must be raised. Relatedly, the possibilities for enhancing the creation of knowledge over simply more information also warrants investigation. The motives of contributors to this knowledge base is one area that may potentially contribute to answers to these questions.

In another critique of the publication efforts of many faculty in higher education, Sykes (1988) suggested that "much of what passes for knowledge creation makes only the most piddling contribution to the pool of human wisdom. Much of 
it is merely humbug" (p. 103). Sykes goes on to imply that few scholars publish their research findings for altruistic purposes. Instead, he suggests, much of the rhetoric surrounding the importance of scholarly writing is little more than an elaborate myth (p. 108) constructed to defend against critics of an easy way to make a living. Relatedly, Mitchell (1993) has suggested that the professional literature may simply serve as a form of cultural capital for PETE faculty in which publications serve as commodities to be bartered for promotion, merit increments, and tenure (i.e., publishing is an end in and of itself; there is no requirement for further evidence of practical or theoretical applications). Metzler (1994) tried to make a similar point when he equated some published studies to the "Russian ruble: They have exchange value in the host economy but are practically worthless in the rest of the world" (p. 443). Rink (1989) expressed a related concern when she observed that many who publish were more interested in a publishable study rather than "professionals with vision — which I believe is a characteristic of true scholarship" (p. 10).

There are many possible explanations why scholars may want to seek publication, but there is little evidence to support the theories. One purpose of this project was to seek such evidence in the words of productive scholars in JTPE. Regardless of the driving reason, there is a related interest in how to be productive. Understanding factors surrounding productivity holds important implications for novice faculty hoping to emulate this behavior, administrators hoping to cultivate productivity, and other concerned professionals.

\section{How To Be Productive}

Attempts to identify the main factors surrounding how to be productive in publishing have gone on for approximately the past 50 years and have typically involved one of two approaches once a pool of participants has been identified. One approach involves a relatively objective correlation of a variety of factors hypothesized to affect research productivity. A second approach involves more subjective results from interviews and questionnaires administered to participants. Cresswell (1985) provides a brief summary of selected findings regarding personal attributes and situational factors of productive scholars in the sciences and social sciences:

\section{Personal Attributes}

1. Conflicting results regarding age and gender

2. Early start (within 10 years of receiving the Doctorate)

3. Early reliance on personal resources

4. Intense private interests as a youth

5. "Gadgeteering" early in life

6. Intrinsic motivation

7. Preference for research over other duties

Situational Factors

1. Influence of the doctoral program for the first 10 years (graduates of major research universities are more productive)

2. Influence of the first job, after the first 10 years of work

3. Regular contact with colleagues

4. Money and release time to support research

5. Competent assistants and faculty 
6. Relief from job stresses such as unappreciative administrators, incompatible colleagues, lack of respect for work done, etc.

7. Time: about $1 / 3$ of time devoted to research activity

For those interested in more extensive reviews of research productivity, the works of Clemente (1973), Fox (1983), Finkelstein (1984), and Creswell (1985) are recommended.

There are several personal attributes that have received attention in studies of professional productivity. In this literature, there are conflicting findings regarding the influence of age and gender over productivity. Both descriptors are confounded by other variables (e.g., era in history, institutional type and mission, rank). Blackburn and Havighurst (1979) found that more important than age was getting an early start in publishing-within the first 10 years after receiving the doctorate. Relatedly, completing a doctorate at a prestigious department does not appear to leave the "indelible mark on the student's career" as suggested by Caplow and McGee (1958, p. 193), but it can have an impact on performance for the first 6 to 10 years after graduation (Long, 1978; Reskin, 1979). After approximately the first 10 years, the influence of the first academic job becomes more prominent (Hargens \& Hagstrom, 1967).

In studies of life histories of eminent male physical and social scientists, common personal attributes reported by Roe $(1953,1972)$ included early reliance on personal resources (e.g., some lost a parent), intense private interests in youth, and involvement with gadgeteering early in life. Pelz and Andrews (1966) and Hunter and Kuh (1984) reported difficulty measuring motivation, but a general trend was noted toward intrinsic rather than extrinsic factors for productive publishers. Blackburn, Behymer, and Hall (1978) and Creswell, Barnes, and Wendel (1982) reported a preference among their participants for research over teaching or other academic activities.

There are several situational factors related to high publication performance that appear repeatedly in the literature. Most prominent is the maintenance of regular contact with colleagues (Behymer, 1974; Braxton, 1983; Finkelstein, 1984; Parker, Lingwood, \& Paisley, 1968; Pelz \& Andrews, 1966). Creswell (1985) noted that interpersonal contacts such as visits and telephone conversations with colleagues (especially research-oriented colleagues) outside the institution (p. 38) were significant influences over research productivity (in terms of written publications). There is, furthermore, a correlation between major research universities and more highly productive faculty (Long 1978; Long \& McGinnis, 1981). Exactly why this relationship exists is uncertain. Some hypothesize that these types of institutions may have recruited talented producers in the first place (cf. Crane, 1965; Long, 1978). It is also possible that major research universities can supply more of the factors that enhance productivity (colleagues, time and money to support research, competent assistants and faculty, easy access to information; Allison \& Stewart, 1974) and relief from job stresses (McKeachie, 1983) that can inhibit productivity (critical and unappreciative administrators, incompatible colleagues, lack of respect for work done, etc.). Lastly, there are reports that how researchers spend their work hours is related to productivity. Pelz and Andrews (1966) suggested that spending an extreme number of professional work hours (either too many or too few) exclusively devoted to research, resulted in reduced productivity. Knorr, Mittermeir, Aicholzer, and Waller (1979) estimate that the 
balance should be approximately one third of professional time devoted to research for maximum productivity.

Also in the literature are results from a study by Crase (1993) of 25 "kinesiologists/physical educators in higher education . . . recognized nationally and internationally for their consistent and influential contributions" (p. 80). Crase indicates 23 characteristics of highly productive scholars in three categories:

Preparation and commitment

1. High degree of perseverance

2. Constant vigilance to new decisions, methodologies, technologies, and initiating change

3. A research focus early in the career

4. Use of leisure to mull over ideas

5. Extensive reading

6. Effectively developed and maintained information retrieval and storage systems

7. A sense of balance across scholarly and family/personal obligations

8. A passion for learning

Support/collaboration

1. Employer recognizes and encourages research focus

2. Surrounded by other creative scholars

3. Assume teaching assignments compatible with research interests

4. Direct master's thesis or doctoral dissertation work compatible with research interests

5. Communicate regularly with other scholars

6. Allow graduate students to assist with basic retrieval and preliminary stages of research

Performance/work

1. Focus on one research project at a time

2. Maintain regular hours for scholarly work

3. Use specific times for scholarly work, free of noise and interruptions

4. Develop and adhere to time schedules

5. Adhere to a work ethic of long hours of concentrated work

6. Think through the process first with an outline and assembling required sources and notes

7. Write regularly to avoid stagnation

8. Write drafts and edit

9. Maintain a steady flow of activity in 3 stages:

- Incubate and sort potential topics

- Write, edit, and rewrite

- Monitor works submitted or in press

The data presented by Crase are somewhat repetitive in places, and Crase does not provide information on the popularity or support for each variable listed. Nonetheless, these do give a sense of how a group of scholars in the sport-related disciplines might be similar to or different from other disciplines in higher education.

There are some common factors between participants in Crase's (1993) work on physical education faculty and the more generic findings across disciplines. The personal attribute of gaining an early start on publishing (perhaps through 
identifying a research focus early in the career) is one common factor. The situational factors of maintaining contact with colleagues and having access to compatible colleagues at the work site are also common factors across disciplines. There appears to be at least one difference across groups. Though Knorr et al. (1979) and Pelz and Andrews (1966) reported the need for balance, the data from the Crase (1993) work suggest some scholars spend a disproportionate amount of time working on or thinking about research. These initial findings indicate that some personal attributes and situational factors of productive scholars may transcend disciplinary focus, whereas other characteristics may be unique to disciplines. Findings regarding the authors in this study may facilitate comparisons of PETE faculty with other faculty in higher education.

\section{Methods and Data Source}

Mitchell (1992a) identified major contributors to JTPE as authors or coauthors of three or more articles across the 1980s. Of this population $(N=44)$, a smaller sample was identified of the most productive contributors (authors or coauthors of four or more articles across the $1980 \mathrm{~s} ; N=28$ ) to this journal, and it is this smaller sample of authors who were selected for this study. It should be noted that no qualitative judgments were made regarding the scholarly value of any given article-I assumed that the editors of the journal have done that. Furthermore, distinctions among solo authors, lead authors, and support authors have not been made in the evaluation of responses given to questions asked in this study. As additional background information on the range of combinations of authorship for the respondents in this study, a profile of author sequence is presented in Table 1.

Respondents completed a mail questionnaire that solicited responses to inquiries about their scholarly behaviors. Responses to the following five prompts will be presented in this paper:

1. You are a productive scholar. There are multiple tasks demanding your attention. Why, therefore, do you write?

2. Relatedly, why do you choose to write for the Journal of Teaching in Physical Education?

3. Your success in publishing interests colleagues. Untenured faculty, in particular, want to learn from you. What is it about you and/or your approach to writing that has led to your publication record?

4. Please comment on the extent to which situational factors have facilitated your productivity.

5. Is there anything else?

Responses were occasionally given in the form of numbered or separated statements. Other responses were given in paragraph form. Hence, I determined the actual number of responses coded. Respondents had difficulty separating personal attributes from situational factors that had an impact on their productivity. For this reason, responses to all related prompts were initially pooled for analysis (i.e., all responses to prompts related to "why" were pooled, and all responses to "how" were pooled separately). Subsequently, a content analysis following a form of the constant comparison method as described by Lincoln and Guba (1985) was performed. Categories used to describe the various responses were drawn from the 
Table 1 Publication Profiles of Respondents

\begin{tabular}{|c|c|c|c|}
\hline Number of publications & Solo author & Coauthor & $\begin{array}{c}\text { Lead author in } \\
\text { multiauthor works }\end{array}$ \\
\hline 11 & 9 & 2 & 0 \\
\hline 10 & 4 & 6 & 1 \\
\hline 8 & 1 & 7 & 4 \\
\hline 7 & 3 & 4 & 2 \\
\hline 7 & 2 & 5 & 2 \\
\hline 6 & 5 & 1 & 1 \\
\hline 6 & 4 & 2 & 1 \\
\hline 6 & 3 & 3 & 0 \\
\hline 6 & 1 & 5 & 1 \\
\hline 5 & 3 & 2 & 2 \\
\hline 5 & 3 & 2 & 1 \\
\hline 5 & 2 & 3 & 2 \\
\hline 5 & 1 & 4 & 2 \\
\hline 5 & 1 & 4 & 1 \\
\hline 5 & 0 & 5 & 3 \\
\hline 4 & 4 & 0 & - \\
\hline 4 & 4 & 0 & - \\
\hline 4 & 3 & 1 & 1 \\
\hline 4 & 2 & 2 & 1 \\
\hline 4 & 2 & 2 & 1 \\
\hline 4 & 2 & 2 & 0 \\
\hline 4 & 1 & 3 & 1 \\
\hline 4 & 1 & 3 & 0 \\
\hline 4 & 1 & 3 & 0 \\
\hline 4 & 0 & 4 & 4 \\
\hline 4 & 0 & 4 & 2 \\
\hline 4 & 0 & 4 & 2 \\
\hline 4 & 0 & 4 & 0 \\
\hline
\end{tabular}

responses rather than being created a priori. The final names assigned to subcategories are drawn from direct quotations from respondents. Lastly, categories were sorted into the predetermined categories as either personal attributes or as situational factors for ease of subsequent comparisons.

After responses were grouped, descriptive data regarding the gender and rank of respondents were tabulated. Cell sizes for gender and rank did not warrant any statistical analysis, but these data are presented for the benefit of full description of the sample involved in this study. These data may provide baseline information for anyone who wishes to add to the study of publishing researchers. When considering the data presented in this study, however, one must remember that $J T P E$ is only one possible outlet for scholarly work; there are other outlets for scholarly research (other journals, papers delivered at conferences and resultant 
proceedings, book chapters, etc.). JTPE was selected for this study because of the low levels of readership of other major journals in the field (e.g., Research Quarterly for Exercise and Sport, Quest) among pedagogy faculty (Metzler \& Freedman, 1985; Mitchell, 1992b).

\section{Results}

There were 28 authors identified in this study, and 24 responded ( $86 \%$ response rate) to a mail questionnaire. Of the 16 males responding, 7 have a $\mathrm{PhD}$, and 9 have a EdD or PED. Among the 8 female respondents, 5 have a PhD and 3 have a EdD or PED. Not all respondents chose to respond to questions regarding age and race, hence, these incomplete data will not be presented.

\section{Why Do You Write?}

In response to the question about why respondents write, a total of 65 responses were recorded-most respondents listed more than one explanation. In fact, only 3 respondents gave 1 reason why they write; 6 respondents gave 2 reasons; 11 gave 3 reasons; 3 gave 4 reasons; and 1 gave 5 reasons.

Two major categories why respondents write were identified, and these were further broken down by subcategories (see Table 2). The first and largest category was identified as "external," in which a total of 36 responses were coded. The second category was identified as "internal," in which a total of 29 responses were coded. Responses are identified by category, rank, and gender in Table 2.

\section{Table 2 Publishing Motives}

\begin{tabular}{|c|c|c|c|c|c|c|c|}
\hline & \multirow[b]{3}{*}{ Statements } & \multicolumn{6}{|c|}{ Rank and gender } \\
\hline & & \multicolumn{2}{|c|}{ Professor } & \multicolumn{2}{|c|}{ Associate } & \multicolumn{2}{|c|}{ Assistant } \\
\hline & & M & $\mathrm{F}$ & M & $\mathrm{F}$ & M & $\mathrm{F}$ \\
\hline \multicolumn{8}{|l|}{ External } \\
\hline Job factors & 13 & 5 & 1 & 1 & 5 & 1 & 0 \\
\hline Professional responsbility & 8 & 4 & 1 & 2 & 1 & 0 & 0 \\
\hline Communication/shape practice & 8 & 5 & 1 & 1 & 1 & 0 & 0 \\
\hline Collaboration opportunity & 4 & 0 & 2 & 0 & 2 & 0 & 0 \\
\hline Program visibility & 3 & 3 & 0 & 0 & 0 & 0 & 0 \\
\hline \multicolumn{8}{|l|}{ Internal } \\
\hline Enjoyment & 12 & 4 & 2 & 3 & 2 & 1 & 0 \\
\hline Personal clarification & 5 & 2 & 1 & 2 & 0 & 0 & 0 \\
\hline Satisfy personal urges & 5 & 2 & 0 & 2 & 1 & 0 & 0 \\
\hline Ego & 5 & 5 & 0 & 0 & 0 & 0 & 0 \\
\hline Guilt & 2 & 0 & 1 & 0 & 1 & 0 & 0 \\
\hline
\end{tabular}

Note. $\mathrm{M}=$ male; $\mathrm{F}=$ female. 
The "external" category was used to identify motives that were located beyond the control of the respondents. The largest subcategory of "external" responses was coded as "job factors" and included 13 statements related to position requirements and the reward structure of higher education. Comments related to the promotion, tenure, and merit system of the employing institution were typical in this category. These explanations most closely resemble what has been called the "publish or perish" standard for university faculty members. This standard for evaluation was not necessarily disliked by respondents. In fact, several respondents made a point of stressing that, although publishing was a job requirement, this job requirement was fully consistent with personal values and goals.

The next two subcategories were related to perceptions of a broader purpose than merely institutional requirements and constraints. The notion of "professional responsibility" was addressed in eight statements. For example, writing was perceived as a professional obligation by one respondent who stated, "I believe that those of us with advanced degrees have an obligation to the profession to express our thoughts and place them in the open arena for others to examine" (Author 7). Relatedly, 8 respondents focused on the need to "communicate/shape practice." "In the eventual hope of improving practice in schools" was the rationale presented by Author 3, whereas another stated, "I wish to shape or be involved in shaping some ideas/methodologies in my professional field" (Author 5). These motives signal the greatest probability for contributions that will become what Lawson (1990) referred to as "useful knowledge." The small numbers of practitioners (at any level) who read professional journals must bring into question the potential of this work for having any impact on professional practice. These may be the authors Kramer (1942) referred to when, after a study of school teachers' use (or, perhaps more accurately, lack of use) of professional literature, he suggested that "a lot of writers of educational material should be told that their efforts are in large part mere busy work" (p. 230).

"Collaboration opportunities," especially in the form of support for specific individuals (e.g., advisees, former students, and younger colleagues) or to work with colleagues were identified in four statements. Interestingly, all of these statements were made by female respondents. This personalized nurturing type of response contrasts with the last category in which three statements addressed nurturing on a different level. In the last category, "program visibility," respondents identified the goal of publicizing or supporting the program, department, or institution. One respondent characterized the importance of writing this way: "It also has political importance for my department which must attract talented students and new faculty" (Author 14). Unquestionably, the sample of respondents studied in this project is too small to draw meaningful conclusions with regard to gender differences of productive publishers in the physical education pedagogy literature. The gender-related differences indicated in these data may provide useful clues to future work exploring the nature of work in higher education as it is experienced by males and females.

The second major category of responses, coded as "internal" included responses that addressed personal motivations to write. The largest subcategory was coded as "enjoyment" because respondents explicitly identified the fact that the process of writing led to feelings of satisfaction, enjoyment, even exhilaration. As one respondent put it, "I enjoy the process of crafting words and stories. To write one good sentence that lays out there just right is one of the consummate joys of intellectual life" (Author 14). 
The next three subcategories each included five statements. The "personal clarification" category was used to identify statements that referred to writing as a means to satisfy curiosity, to clarify thoughts, or to learn. One respondent said, "To paraphrase DeCartes [sic]: I think, therefore I write. Writing for scholarly journals helps me to clarify my thoughts" (Author 16). Another respondent went further to suggest that "the peer review process allows me to learn from others, while testing the quality of my ideas and work" (Author 6).

A related subcategory was identified by the apparent motive to "satisfy personal urges." Meeting the demands of personal curiosity, or serving as a "creative outlet" (Author 17) were typical responses in this subcategory. These explanations for publishing may reflect the "specialization and fragmentation" (cf. Lawson, 1991) faced by faculty members at their home institution. Without access to colleagues who share a common research focus or sense of professional mission on their own campus (including in their own department), the professional literature may provide the next available level of competent interaction.

The last two categories were split along gender lines and signal additional, potentially interesting lines of future inquiry into the different accounts of the professorial experience. The subcategory "ego" was used to include statements that referred to the motivating drive to see one's name in print, to see a finished product that is published, or to achieve status in the eyes of peers. All of these statements were made by males. The subcategory of "guilt" was used to describe two responses given by female respondents. One respondent stated that she occasionally wrote because someone had asked her to do so, and among several competing emotions, she expressed the feeling that "I feel guilty saying no" (Author 8). For the other respondent, the notion of guilt was expressed more strongly: "Even with tenure, there is the guilt and angst of not writing which leads to less satisfaction with myself as a professional" (Author 15).

Authors who publish in JTPE identified a variety of reasons why they write. Many explanations have been discussed in the literature previously, and some new motives were noted. However, there are many possible outlets for these writers, and most have presented their work in one or more of these alternative modes. Attention will now be shifted to motives for publishing in this particular journal.

\section{Why Do You Write for This Journal?}

In response to the question about why the authors write for JTPE, 42 responses were recorded. As was true with the first question, many respondents listed more than one explanation. For this question, 12 respondents gave only 1 reason why they write for JTPE; 7 gave 2 reasons; 4 gave 3 reasons; and 1 gave 4 reasons. Six categories were identified and are presented in Table 3.

The first and largest category was identified as "journal audience" for which 14 statements were coded. Respondents typically referred to the nature of the readers of this journal as "appropriate" (Author 3), "logical" (Author 23), "suitable" (Author 6), or generally as the group of peers or colleagues of most interest to the authors. Clearly related to the first category, but using a different phrasing, JTPE was identified as the "most appropriate journal" in 12 statements. In most cases, respondents used these exact words in describing the journal. One respondent identified JTPE as "the journal that most consistently deals with the concerns of teacher educators in P. Ed." (Author 2). These first two categories are entirely consistent 


\begin{tabular}{|c|c|c|c|c|c|c|c|}
\hline & \multirow[b]{3}{*}{ Statements } & \multicolumn{6}{|c|}{ Rank and gender } \\
\hline & & \multicolumn{2}{|c|}{ Professor } & \multicolumn{2}{|c|}{ Associate } & \multicolumn{2}{|c|}{ Assistant } \\
\hline & & M & $\mathrm{F}$ & M & $\mathrm{F}$ & M & $\mathrm{F}$ \\
\hline Journal audience & 14 & 5 & 1 & 5 & 3 & 0 & 0 \\
\hline Most appropriate journal & 12 & 5 & 2 & 3 & 1 & 1 & 0 \\
\hline Journal prestige & 8 & 3 & 0 & 2 & 2 & 1 & 0 \\
\hline A facilitating journal & 4 & 0 & 2 & 2 & 0 & 0 & 0 \\
\hline To support the journal & 3 & 2 & 0 & 1 & 0 & 0 & 0 \\
\hline Personal obligation & 1 & 0 & 1 & 0 & 0 & 0 & 0 \\
\hline
\end{tabular}

Note. $\mathrm{M}=$ male $\mathrm{F}=$ female.

with all of the "external" motives for publishing and with the "internal" motive to seek personal clarification.

In the third category, eight statements were coded because of an explanation for publishing in JTPE related to "journal prestige." Descriptors used in responses included words and phrases like "lead journal" (Author 4), "major conduit" (Author 12), "one of the foremost journals in the area of pedagogy" (Author 20), and "a premier outlet for the work I do" (Author 22). These statements could be interpreted either as evidence of ego involvement or as another way of seeking the widest and most appropriate audience.

The concept of JTPE being a "facilitating journal" was identified in four statements. One respondent noted the monograph as being a useful format for disseminating some types of information and that JTPE was "clearly the most receptive journal for physical education curriculum articles" (Author 24). Another respondent identified the facilitating nature of the journal because of the acceptance of work that was rejected elsewhere. In addition, there was the observation that "the time from submission to publication is usually quick" (Author 16).

The final two categories of motives for publishing in JTPE each included few statements. A sense of obligation was a common theme for each of these categories, but each appeared distinct enough to warrant separate mention. To "support the journal" was identified by 3 respondents. Phrased in slightly different ways, there was an expression of commitment to what the journal represented as a forum for sharing research on teaching and teacher education in physical education. In the last category, one respondent referred to a slightly different obligation; this respondent expressed a felt obligation to the profession, with JTPE simply being an appropriate outlet to best meet this obligation.

As has been suggested by authors speculating on the motives of scholars, a variety of purposes drive efforts to publish. Attention will now be shifted away from "why" to look at "how" these successful writers have achieved their success. First, attributes of the individuals themselves will be presented. Second, aspects of the setting in which these scholars' work will be presented. 


\section{Personal Attributes}

A total of 75 responses were coded as addressing details about "personal attributes" facilitating productivity. Most respondents listed more than one personal attribute in their explanation. In fact, only 4 respondents gave 1 descriptor of personal attributes leading to success in publishing; 4 gave 2 descriptors; 4 gave 3 descriptors; 7 gave 4 descriptors; 3 gave 5 descriptors; and 1 gave 8 descriptors. Of the 24 respondents in this study, only one individual was unable to provide any descriptors of "personal attributes" leading to a successful publication record.

There were eight categories identified as descriptors of "personal attributes" leading to success in scholarly productivity. A list of the categories of descriptors used is presented in Table 4.

The most prominent responses, identified in 22 comments, involved the concept of "commitment." In this category, respondents explicitly mentioned the idea of having a commitment; they also described the need to have a "focus" (Author 6, Author 12), and described writing as a priority in their professional lives (Author 16, Author 24). Respondents repeatedly mentioned the extent to which one could be successfully productive, regardless of circumstance, if the internal drive was there. The next most common explanation was coded as "organization and planning," in which 18 statements were identified. Included in this category, for example, was explicit reference to "good organizational skills" (Author 8, Author 19 ), the ability to "create blocks of time" (Author 6), and having a place to go to write without interruption. "Good content" was identified in 15 statements as the next most common response. In this category, respondents described the attribute of having something to say (Author 3); preferably something of help to the profession (Author 10). The notions of asking good questions and using appropriate meth-

\section{Table 4 Personal Attributes}

\begin{tabular}{|c|c|c|c|c|c|c|c|c|c|}
\hline & \multirow[b]{3}{*}{ Statements } & \multicolumn{8}{|c|}{ Rank and gender } \\
\hline & & \multicolumn{2}{|c|}{ Professor } & \multicolumn{2}{|c|}{ Associate } & \multicolumn{2}{|c|}{ Assistant } & \multicolumn{2}{|c|}{ N/A } \\
\hline & & $\mathbf{M}$ & $\mathrm{F}$ & M & $\mathrm{F}$ & M & $\mathrm{F}$ & M & $\mathrm{F}$ \\
\hline Commitment & 22 & 13 & 4 & 4 & 1 & 0 & 0 & 0 & 0 \\
\hline $\begin{array}{l}\text { Organization and } \\
\text { planning }\end{array}$ & 18 & 7 & 4 & 2 & 3 & 0 & 0 & 2 & 0 \\
\hline Good content & 15 & 5 & 2 & 3 & 4 & 0 & 0 & 1 & 0 \\
\hline Persistent writing & 10 & 5 & 2 & 1 & 1 & 1 & 0 & 0 & 0 \\
\hline Enjoyment & 6 & 0 & 1 & 2 & 2 & 1 & 0 & 0 & 0 \\
\hline Read & 2 & 0 & 0 & 1 & 0 & 0 & 0 & 1 & 0 \\
\hline Self-confidence & 1 & 0 & 0 & 0 & 1 & 0 & 0 & 0 & 0 \\
\hline Guilt & 1 & 0 & 0 & 0 & 1 & 0 & 0 & 0 & 0 \\
\hline Total & 75 & 30 & 13 & 13 & 13 & 2 & 0 & 4 & 0 \\
\hline
\end{tabular}

Note. $\mathrm{M}=$ male $; \mathrm{F}=$ female. 
ods were also mentioned (Author 13). A category of statements coded as "persistent writing" contained 10 comments. The thrust of comments in this category was to simply write, to do it regularly — even daily — and to be persistent with editing and rewriting even if initially rejected.

Although all respondents consider writing to be hard work, many consider their success to be at least partially attributable to the fact that they enjoy the task. The concept of "enjoyment" of the process of writing for publication is self-evident, and was described in six statements. The remaining categories received minimal support but warrant mention. Two respondents believed that their success could be tied to the fact that they "read." These respondents spoke of reading widely to inform their research and writing needs. The final categories each involved one respondent. One attributed success to personal self-confidence that resulted in staying with the tasks of writing, editing, and rewriting until successfully published. Lastly, one respondent described the feeling of "guilt" as the driving personal attribute that has led to success in publishing.

\section{Situational Factors}

A total of 88 responses were coded as "situational factors" facilitating productivity. As was true with the first question, many respondents listed more than one explanation in their responses. In this regard, 1 respondent described 1 "situational factor" for success in getting published in JTPE; 5 gave 2 factors; 5 gave 3 factors; 3 gave 4 factors; 1 gave 5 factors; 2 gave 6 factors; 1 gave 7 factors; 1 gave 8 factors; and 2 gave 9 factors. There were 3 respondents for whom no situational factors could be identified surrounding successful publishing in JTPE. Eleven categories were identified and are presented in Table 5.

The first and largest category was identified as "colleague/mentor support," involving 29 statements. Respondents most emphatically mentioned the benefit of mentors and colleagues providing editorial feedback on ideas and draft manuscripts. The category "students" was the next most common category, with 14 statements. Respondents mentioned both graduate and undergraduate students in roles of interactive audience and sometime assistants in the thinking, researching, and writing process. "Institutional rewards" were identified in 8 statements where respondents spoke of promotion and merit salary rewards. Comments coded as "Opportunity/luck" were the next group of responses identified, again with 8 statements. Some respondents spoke of simply having been in the right place at the right time as a factor in their productivity. "Technical equipment" was identified in 6 statements. Reference was typically made to computers and video equipment as facilitators of the research and writing enterprise.

"Preparation" was identified in 5 statements and appeared as a descriptor in two time periods. Some respondents described the value of English teachers who had pushed them to write well (Author 6, Author 10), and others spoke of the value of their graduate work either through the "doctoral training" (Author 8) or by means of a good model in the form of the doctoral advisor (Author 1). "Money" was the next most common response, with 5 statements. Small grants and related support for research costs were discussed in this category. "Release time/teaching load" was the next category identified, with 5 statements. This category is self-explanatory and was separated from "institutional rewards" because these respondents typically value the teaching enterprise and therefore may not necessarily consider the 
Table 5 Situational Factors

\begin{tabular}{|c|c|c|c|c|c|c|c|c|c|}
\hline & \multirow[b]{3}{*}{ Statements } & \multicolumn{8}{|c|}{ Rank and gender } \\
\hline & & \multicolumn{2}{|c|}{ Professor } & \multicolumn{2}{|c|}{ Associate } & \multicolumn{2}{|c|}{ Assistant } & \multicolumn{2}{|c|}{ N/A } \\
\hline & & M & $\mathrm{F}$ & M & $\mathrm{F}$ & M & $\mathrm{F}$ & M & $\mathrm{F}$ \\
\hline $\begin{array}{l}\text { Colleague/mentor } \\
\text { support }\end{array}$ & 29 & 11 & 4 & 3 & 8 & 1 & 0 & 2 & 0 \\
\hline Students & 14 & 6 & 2 & 2 & 3 & 1 & 0 & 0 & 0 \\
\hline Institutional rewards & 8 & 4 & 1 & 1 & 1 & 1 & 0 & 0 & 0 \\
\hline Opportunity/luck & 8 & 1 & 3 & 1 & 3 & 0 & 0 & 0 & 0 \\
\hline Technical equipment & 6 & 2 & 1 & 1 & 1 & 1 & 0 & 0 & 0 \\
\hline Money & 5 & 1 & 1 & 1 & 1 & 1 & 0 & 0 & 0 \\
\hline $\begin{array}{l}\text { Release time/teaching } \\
\text { load }\end{array}$ & 5 & 1 & 0 & 2 & 1 & 1 & 0 & 0 & 0 \\
\hline Preparation & 5 & 2 & 1 & 0 & 1 & 1 & 0 & 0 & 0 \\
\hline Library holdings & 4 & 0 & 2 & 0 & 1 & 1 & 0 & 0 & 0 \\
\hline Research assistant & 3 & 0 & 1 & 1 & 0 & 1 & 0 & 0 & 0 \\
\hline Competent secretary & 1 & 0 & 1 & 0 & 0 & 0 & 0 & 0 & 0 \\
\hline Totals & 88 & 28 & 17 & 12 & 20 & 9 & 0 & 2 & 0 \\
\hline
\end{tabular}

Note. $\mathrm{M}=$ male; $\mathrm{F}=$ female.

reduced teaching load a reward. "Library holdings" was the next category of responses, with 4 statements. Access to a "research assistant" was a less common response, with only 3 statements. Lastly, one respondent identified access to a "competent secretary" as one of the situational factors leading to a successful publishing record.

\section{Discussion, Conclusions, and Implications}

The purpose of this study was to determine why and how a sample of PETE scholars manage to be productive writers. Of the two the most common explanations why PETE scholars are productive, one was a predictable response and the other one less so. Job expectations and reward structures are reasonably predictable explanations why scholars strive to be productive. Somewhat less common is the description of how these scholars enjoy the process. More typical comments involve concerns and complaints regarding the lack of time and other resources to meet the productivity expectations. These results correlating success and enjoyment highlight the value in finding a career in which the key tasks are a labor of love rather than drudgery.

Only two of the hypothesized motives for publishing were not supported. First, the pursuit of personal power in the profession through recognition was not explicitly mentioned. Second, the attempt to establish a career identity, especially as distinct from the identity of teacher/coach, was not explicitly mentioned. There 
are three possible explanations for these omissions. First, it is possible that these are not bona fide motives for authors. Second, it is possible that these motives are present but were simply not phrased in a way that was easily identifiable. A third possibility is that although these motives are real, authors are unwilling to be identified with these explanations.

Several motives for publishing may now be added to the list. First, "professional responsibility" can be added as a separate category from guiding and improving practice. The existing category implies the intention that practice will be influenced by the writing. The new category implies that the writing will simply inform others as to how practice could be or should be changed. Readers are then free to make their own choices whether to apply the opinions expressed. That is, the authors' obligation rests with making these "informed" opinions public; the implementation of these opinions is not perceived to be the sole responsibility of the authors.

The "collaboration opportunity" is also a new motive. For future clarification, it may be appropriate to separate the nurturing of novice professionals from the motive to pursue peer colleagues to share an intellectual experience. Each of these motives involves collaborative relationships, but different roles are played by participants in the collaboration. The collaborations in which respondents were involved included both within- and across-institutional efforts. More specific insights into exactly who was chosen for collaboration and why was beyond the scope of the present investigation. A closer examination of these relationships may inform the quest to identify programs that have the necessary resources to remain in the business of teacher education (see also Locke, 1995).

Writing as a contribution to building one's ego is different from motives listed previously. Lacking a common language to address these issues, however, it is possible that this is merely an alternative way to talk about peer pressure, power acquisition, or for establishing a career identity.

Lastly, "guilt" is a new addition to the list of motives for publishing. Peer pressure is a similar concept, but, for the respondents in the present study, the guilt described seemed to come from an internalized and self-imposed value system rather than from any external sources.

Isolating explanations for productivity is a challenging task. A variety of variables overlap and interact, resulting in the complex fabric that can facilitate productive scholarly activity. For the respondents in this study, the most significant factor identified involved the contributions of colleagues and mentors. Nearly as significant is the notion of commitment. The relationship between these variables is not clear. It is possible that some respondents made a commitment to this role responsibility and then sought out situations that would help them reach their goal. In other cases, colleagues and mentors may have shaped the goals of individuals to aspire to publication. In either event, these are clearly the most significant factors leading to productivity. Other major variables may be related to the notion of commitment. The major explanations for productivity offered by respondents in this study reflect priorities similar to those described in work reviewed earlier.

Once the decision has been made to pursue publication, being organized and planning ahead are simply means with high probability for leading to a successful end. The persistence of reworking drafts and ideas is another way of operationalizing the notion of making a commitment or setting a goal. 
With regard to the notion of commitment, many respondents in this study described a situation in which they appeared to spend a disproportionate amount of time involved with the task of writing for publication. This finding runs contrary to descriptions of successful researchers in the social sciences where a balance of only about one third of professional time is recommended (Knorr et al, 1979; Pelz $\&$ Andrews, 1966). One respondent provided an interesting characterization of the time commitment:

I know of only a handful (two-three) of people in our business who teach well, have administrative responsibilities, nurture graduate students, collect and analyze data, write reports, articles and books, and also manage to have private lives that are rich and satisfying. Something has to give. Usually it is the private life of wife, husband, parent, lover, friend, son, or daughter. Not doing those things (at least, not doing them well) yields time and energy. It is a trade with the devil. He comes to collect—eventually! (Author 14)

It is interesting to note that the commitment noted in this study supports the findings reported by Crase (1993) in his study of physical education faculty. The possibility exists that these work patterns represent the struggle for credibility, recognition, and respect by physical educators in higher education - a struggle waged against marginalization more commonly identified as the fight of physical educators at the $\mathrm{K}-12$ level.

Findings regarding how to be productive have important implications for administrators, novice faculty, and others interested in publishing and the costs associated with higher education. Administrators are frequently concerned with securing resources for their academic unit. Resources are increasingly more available to units where faculty members are seen as productive. Furthermore, Many institutions are being forced to fulfill their academic mission on tighter budgets. Hence, finding cost-effective strategies to help faculty meet their role demands is important. The findings from this study point to the somewhat surprising fact that high-cost interventions such as release time from teaching, technical equipment, money, research assistants, large library holdings, and so forth, are neither necessary nor sufficient for faculty members to be active scholars. Although these variables can be assets, and can help already productive faculty members to do more, there is no evidence that these expenses will help faculty members to become productive if they are not already predisposed to be involved with research and writing for publication.

Where, then, does one find new faculty members with an interest and aptitude for publishing? There is some support for looking to major research universities for recent graduates, specifically to the "high prestige" institutions (Mitchell, 1992a). Individuals from these schools seem to have a higher chance of bringing with them the experience of having already published, a predisposition to value this activity, a support network of colleagues (often former fellow students), and a mentor.

Administrators do not always have the luxury of refitting their department with new hires. In many cases, departments are fully tenured and leverage over how faculty members perform is minimized. Mindful of tight budget restrictions, administrators may be best advised to encourage faculty members to enter into collaborative relationships with colleagues within departments, across disciplines, and even across campuses. Novice faculty members, too, should be aware of the importance of securing and maintaining relationships with others who will sup- 
port them in their quest to be productive scholars. There is at least one other costeffective strategy that can be implemented: with regard to teaching assignments, there appears to be a positive result when faculty members are focused and given the chance to interact with students who have shared interests.

Studies of research productivity can help individuals who aspire to careers in higher education in at least three ways. First, it is important to be aware that writing for publication is a role responsibility that is a significant determinant of success in higher education. It is therefore important that some guidance be provided in forming a subjective warrant for work as a faculty member. Second, academic advisors need to be aware of the types of programs that have demonstrated the highest probability for giving their graduates the requisite skills for success. Clues to such programs exist in the literature (cf. Hasbrook \& Loy, 1983; Massengale \& Sage, 1982; Mitchell, 1992a). Third, identifying strategies for selecting mentors and colleagues and for maximizing the potential benefits of these relationships need to be discussed. This is an area identified as significant in the lives of other teacher educators by Ducharme (1993), but there is less information available for providing direction in higher education. Much of the work related to mentoring in education has focused on how faculty in higher education can mentor beginning teachers working in the K-12 schools (cf., Bey \& Holmes, 1992).

People responsible for overseeing the functioning of colleges and universities can also be informed by research on scholarly productivity. Provosts, university presidents, and boards of regents, for example, may gain insights into the merits of requests by departments for funds. It is apparent that spending money on departments with a proven track record for scholarly activity will have a higher probability of showing a favorable return. Conversely, spending on a department without such a history of activity in the hope of stimulating action will be unlikely to be a sufficient intervention.

The magic formula for creating a productive researcher, if such a potion exists, has not yet been discovered. There are clues to different aspects of what is involved with this type of performance, but no recipe has been shown to be foolproof. It is also important to exercise caution in applying the findings from studies of productive scholars. Publishing in the professional literature can become an institutionalized, objectified, and reified artifact of the field that can backfire on its creators (cf. Berger \& Luckmann, 1966). Professionals taking the findings of "problem-solving" work like this study are at risk when "problem-setting" questions are ignored. Boyer's (1990) attempt to redefine scholarship is one example of an effort to revisit some of the assumptions and foundational beliefs that drive the pursuit of publications in higher education.

For those authors trying to communicate ideas, shape practice, or provide visibility for their program, other questions may be identified. For example, have these authors considered the size of the audience they reach through this journal? Relatedly, how many people must be influenced for an author to consider the work "successful"? For some teachers, to change the life of one student is success. For many professional entertainers, success is measured in the thousands of paying patrons. Where is the standard for productive publishers of the physical education pedagogy literature? Do these authors even think about the applications or influence of their work? If these authors do not think about the merit of their work, will their efforts be supported and valued by the community? Current movements across the country to hold faculty in higher education accountable for their time suggest a 
need for attention to these questions. And there are other questions that bring together the study of creation and application of knowledge for practice, job satisfaction, and societal values of work performed.

Lawson (1993) suggested that as societal needs change, schools and teachers will be forced to change. An important question, therefore, is how will teachers change-in what ways and with whose assistance? The "pro-research bias" identified by Lawson (1993, p. 368) in the physical education profession, where published research is perceived as necessary in pointing the way for practice, is flawed. Practitioners tend not to look to the research for insight into their practice, and few of the productive authors in PETE have expressed this expectation for their work.

Clearly, the research and practice relationship needs to be better understood. If practitioners are to be favorably influenced to meet the changing needs of society, the influence is not likely to come from the publication of research studies. In fact, Locke (1985) argued that searching for solutions to school problems and helping teachers decide what is best, was a misunderstanding of the purpose of research. Other means for exerting an influence over practice are required.

There remains a concern over the value of the research and publication enterprise. In defense of the publishing enterprise, many authors are themselves practitioners (as teacher educators working to prepare new teachers and teacher educators). Consequently, to the extent to which their own practice is enhanced through gaining clarity in their thoughts, there is an impact on the profession. This interpretation may be closest to Boyer's (1990) notion of the scholarship of teaching (p. 23). Future estimates of the value of published work may need to include the impact on one's own professional practice (e.g., advising, further research along a related line, teaching, and professional service contributions) as a valid measure of the impact and merit of professional writing. Indeed, portfolio assessments for promotion and tenure decisions are, in some cases, already structured with the expectation that the links between a line or lines of research and other professional responsibilities (e.g., committee service, teaching) will be visible.

\section{References}

Allison, P.D., \& Stewart, J.A. (1974). Productivity differences among scientists: Evidence for accumulative advantage. American Sociological Review, 39, 596-606.

Behymer, C. (1974). Institutional and personal correlates of faculty productivity. Unpublished doctoral dissertation, University of Michigan.

Berger, P., \& Luckmann, T. (1966). The social construction of reality: A treatise in the sociology of knowledge. Garden City, NY: Anchor Books.

Bey, T.M., \& Holmes, C.T. (Eds.) (1992). Mentoring: Contemporary principles and issues. Reston, VA: Association of Teacher Educators.

Blackburn, R., Behymer, C., \& Hall, D. (1978). Research notes: Correlates of faculty publications. Sociology of Education, 51, 132-141.

Blackburn, R.T., \& Havighurst, R.J. (1979). Career patterns of U.S. male academic social scientists. Higher Education, 8, 553-572.

Bok, D. (1986). Higher learning. Cambridge, MA: Harvard University Press.

Bowen, H.R., \& Schuster, J.H. (1986). American professors: A national resource imperiled. New York: Oxford University Press.

Boyer, E.L. (1990). Scholarship reconsidered: Priorities of the professoriate. Princeton, $\mathrm{NJ}$ : The Carnegie Foundation for the Advancement of Teaching. 
Braxton, J.M. (1983). Department colleagues and individual faculty publication productivity. The Review of Higher Education, 6, 115-128.

Burch, B.G. (1989). Perceptions of the role and scholarly reputation of the education professoriate. In R. Wisniewski \& E.R. Ducharme (Eds.), The professors of teaching (pp. 87-104). Albany: State University of New York Press.

Caplow, T., \& McGee, R.J. (1958). The academic marketplace. Garden City, NY: Anchor Books.

Carnegie Foundation for the Advancement of Teaching. (1985). The faculty: Deeply troubled. Change, 17, 31-34.

Clemente, F. (1973). Early career determinants of research productivity. American Journal of Sociology, 79, 400-419.

Clifford, G.J., \& Guthrie, J.W. (1988). Ed school: A brief for professional education. Chicago: The University of Chicago Press.

Crane, D. (1965). Scientists at major and minor universities: A study of productivity and recognition. American Sociological Review, 30, 699-714.

Crase, D. (1993). Highly productive scholars: What drives them toward success? Journal of Physical Education, Recreation \& Dance, 64(6), 80-82.

Creswell, J.W. (1985). Faculty research performance: Lessons from the sciences and the social sciences (ASHE-ERIC Higher Education Rep. No. 4). Washington, DC: Clearinghouse on Higher Education.

Creswell, J.W., Barnes, M.W., \& Wendel, F. (1982, March). Correlates of faculty research productivity. Paper presented at the meeting of the American Educational Research Association, New York.

Ducharme, E.R. (1993). The lives of teacher educators. New York: Teachers College Press.

Ducharme, E.R., \& Agne, R.M. (1982). The education professoriate: A research-based perspective. Journal of Teacher Education, 33, 300-336.

Finkelstein, M.J. (1984). The American academic profession. Columbus, OH: Ohio State University Press.

Fox, M.F. (1983). Publication productivity among scientists. Social Studies of Science, 13, 285-305.

Freeman, B.C. (1977). Faculty women in the American university: Up the down staircase. In P.G. Altback (Ed.), Comparative perspectives on the academic profession (pp. 160-190). New York: Praeger.

Hargens, L.L., \& Hagstrom, W.O. (1967). Sponsored and contest mobility of American academic scientists. Sociology of Education, 40, 24-38.

Hasbrook, C.A., \& Loy, J.W. (1983). Publication and citation as measures of academic quality among graduate programs in physical education. Quest, 35, 131-144.

Hunter, D.E., \& Kuh, G.D. (1984). A profile of prolific scholars in higher education. Paper presented at the meeting of the American Educational Research Association, New Orleans.

Jencks, C., \& Riesman, D. (1969). The academic revolution (2nd ed.). Chicago: The University of Chicago Press.

Knorr, K.D., Mittermeir, R., Aicholzer, G., \& Waller, G. (1979). Individual publication productivity as a social position effect in academic and industrial research units. In F.M. Andrews (Ed.), Scientific productivity: The effectiveness of research groups in six countries (pp. 55-94). Cambridge, MA: Cambridge University Press.

Kramer, J.H. (1942). Professional reading: A summer school group of 77 teachers confess how little education literature they cover. Clearing House, 17, 228-230.

Ladd, E.C., \& Lipset, S.M. (1976). Nearly all professors are satisfied with their choice of an academic career. Chronicle of Higher Education, 12(10), 11. 
Lawson, H.A. (1990). Sport pedagogy research: From information-gathering to useful knowledge. Journal of Teaching in Physical Education, 10, 1-20.

Lawson, H.A. (1991). Specialization and fragmentation among faculty as endemic features of academic life. Quest, 43, 280-295.

Lawson, H.A. (1993). Teachers' uses of research in practice: A literature review. Journal of Teaching in Physical Education, 12, 366-374.

Lincoln, Y.S., \& Guba, E.G. (1985). Naturalistic inquiry. Beverly Hills, CA: Sage.

Locke, L.F. (1985, August). Research and the improvement of teaching: The professor as the problem. Paper presented at the annual meeting of the AIESEP, Adelphi University, Garden City, NY. (ERIC Reproduction Service No. ED 266 114)

Locke, L.F. (1995, November). The teacher educator's guide to program problems and program disasters. Paper presented at the National Conference on Teacher Education in Physical Education, Morgantown, WV.

Long, J.S. (1978). Productivity and academic position in the scientific career. American Sociological Review, 43, 889-908.

Long, J.S., \& McGinnis, R. (1981). Organizational context and scientific productivity. American Sociological Review, 46, 422-442.

Massengale, J.D., \& Sage, G.H. (1982). Departmental prestige and career mobility patterns of college physical educators. Research Quarterly for Exercise and Sport, 53, 305312.

McKeachie, W.J. (1983). Faculty as a renewable resource. In R.G. Baldwin \& R.T. Blackburn (Eds.), College faculty: Versatile human resources in a period of constraint (New Directions for Institutional Research No. 40, pp. 57-66). San Francisco: Jossey-Bass.

Metzler, M.W. (1994). Scholarship reconsidered for the professoriate of 2010. Quest, 46, 440-455.

Metzler, M.W., \& Freedman, M.S. (1981). Editor's pages. Journal of Teaching in Physical Education, Introductory Issue, 1-2.

Metzler, M.W., \& Freedman, M.S. (1985). Here's looking at you PETE: A profile of physical education teacher education faculty. Journal of Teaching in Physical Education, 4, 123-133.

Mitchell, M.F. (1992a). A descriptive analysis and academic genealogy of major contributors to JTPE in the 1980s. Journal of Teaching in Physical Education, 11, 426-422.

Mitchell, M.F. (1992b). Scholarly behaviors of physical education methods teacher educators in Ohio. Journal of Teaching in Physical Education, 11, 303-314.

Mitchell, M.F. (1993). Linking teacher educators, knowledge, and the quality of practice in schools. Journal of Teaching in Physical Education, 12, 399-412.

Mitchell, M.F., \& Lawson, H.A. (1986). Career paths and role orientations of professors of teacher education in physical education. In M. Piéron \& G. Graham (Eds.), Sport pedagogy (The 1984 Olympic Scientific Congress proceedings, Vol. 6, pp. 41-46). Champaign, IL: Human Kinetics.

Parker, E.B., Lingwood, D.A., \& Paisley, W.J. (1968). Communication and research productivity in an interdisciplinary behavioral science research area. Stanford: Stanford University, California Institute for Communication Research; Springfield, VA: National Technical Information Service.

Pelz, D.C., \& Andrews, F.M. (1966). Scientists in organizations. New York: Wiley.

Reskin, B.F. (1979). Academic sponsorship and scientists' careers. Sociology of Education, 52, 129-146.

Rink, J.E. (1989, October). Two decades of research on teaching: Where are we now? Paper presented at the R. Tait McKenzie Symposium on Sport Pedagogy, Knoxville, TN. 
Roe, A. (1953). The making of a scientist. New York: Dodd Mead.

Roe, A. (1972). Patterns in productivity of scientists. Science, 176, 940-941.

Scott, M.W. (1986). A study to profile the features of physical educators in higher education by institutional level. Unpublished doctoral dissertation, University of North Carolina at Greensboro.

Seldin, P. (1984). Faculty evaluation: Surveying policy and practices. Change, 16(3), 28-33.

Sykes, C.J. (1988). ProfScam: Professors and the demise of higher education. New York: St. Martin's Press.

\section{Acknowledgment}

Hal Lawson's assistance in early aspects of this project helped shape the final product. Thanks are also due to Judy Rink and Pam Weiss for feedback and to the productive authors who shared insights into their professional behaviors. Earlier versions of different portions of this paper were presented at the annual national meeting of the American Educational Research Association, New Orleans, LA, April 1994, and at the 10th International Commonwealth Games Scientific Conference, Victoria, British Columbia, Canada, August 1994. 